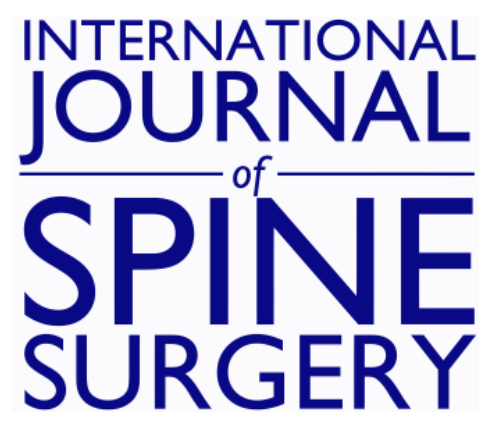

\title{
L5 Radiculopathy After Formal Reduction of High-Grade SDSG Type 5 and 6 L5-S1 Isthmic Spondylolisthesis with 2-Year Follow-Up
}

Carlos Eduardo Gonçalves Barsotti, Réjelos Charles Aguiar Lira, Rodrigo Mantelatto Andrade, Alexandre Penna Torini and Ana Paula Ribeiro

Int J Spine Surg 2021, 15 (4) 645-653

doi: https://doi.org/10.14444/8085

http://ijssurgery.com/content/15/4/645

This information is current as of April 26, 2023.

Email Alerts Receive free email-alerts when new articles cite this article. Sign up at:

http://ijssurgery.com/alerts

The International Journal of Spine Surgery

2397 Waterbury Circle, Suite 1,

Aurora, IL 60504, Phone: +1-630-375-1432 


\title{
L5 Radiculopathy After Formal Reduction of High-Grade SDSG Type 5 and 6 L5-S1 Isthmic Spondylolisthesis with 2-Year Follow-Up
}

\author{
CARLOS EDUARDO GONÇALVES BARSOTTI, MD, ${ }^{1,2}$ RÉJELOS CHARLES AGUIAR LIRA, MD, ${ }^{1}$ \\ RODRIGO MANTELATTO ANDRADE, MSC, ${ }^{2}$ ALEXANDRE PENNA TORINI, MD, ${ }^{1,3}$ ANA PAULA \\ RIBEIRO, MD, PHD 3,4 \\ ${ }^{I}$ Member of the Spine Group, Institute of Medical Assistance to the State Public Hospital Servant (IMASPS), São Paulo, Brazil, ${ }^{2}$ Clinical Rehabilitation Center \\ in Scoliosis, Campinas, São Paulo, Brazil, ${ }^{3}$ Post-Graduate Program in Health Science, Biomechanics and Musculoskeletal Rehabilitation Laboratory, University \\ Santo Amaro, São Paulo, Brazil, ${ }^{4}$ University of Sao Paulo, School of Medicine, São Paulo, Brazil
}

\begin{abstract}
Background: Surgery is the main treatment for patients with high-grade L5-S1 isthmic spondylolisthesis, which can result in neurologic complications, but little is known about its clinical course. The present study evaluated the presence of L5 radiculopathy in high-grade L5-S1 spondylolisthesis in adults in pre- and postoperative periods and after a 2-year follow-up.

Methods: A series of 16 patients who underwent reduction and instrumented fusion for high-grade 5 and 6 spondylolisthesis between 2018 and 2019 were retrospectively evaluated in the pre- and postoperative periods as well as after 6 weeks, 3 months, 6 months, and 1 and 2 years of follow-up. Clinical and surgical data on possible neurological complications of L5 radiculopathy were prospectively collected.

Results: The age was $20.1 \pm 12.0$ years, and preoperative L5-S1 slip was $89.0 \%$. Five patients presented motor deficit in the preoperative period. In the immediate postoperative period, 9 patients $(56 \%)$ experienced motor deficits or worsening of the preoperative condition. At the 6-week follow-up, only 1 patient showed resolution of the motor deficit. Three patients presented healed motor deficits after 3 months, and 1 patient demonstrated a healed L5 motor radiculopathy after 6 months. At the 1-year follow-up, only 1 patient exhibited an L5 radiculopathy motor deficit, and at the 2-year follow-up, none of the patients exhibited an L5 radiculopathy motor deficit.

Conclusion: L5 radiculopathy was frequent in the preoperative period and increased after reduction and instrumented fusion of high-grade L5-S1 spondylolisthesis in the postoperative period and in the 6-week follow-up. Three and 6 months after the surgery, there were consecutive motor improvements. After 2 years of follow-up, no patients showed neurological deficit of L5 radiculopathy.

Level of Evidence: 2.

Clinical Relevance: This is the first study reporting a reduction in complications of L5 neurological motor deficit over a 2-year follow-up in high-grade L5-S1 spondylolisthesis in young adults.

Complications

Keywords: spondylolisthesis, radiculopathy, neurological deficit, spine
\end{abstract}

\section{INTRODUCTION}

Spondylolisthesis has an incidence rate that varies from $4.4 \%$ to $39.7 \%$ in different populations; it is characterized by vertebral slippage from a variety of causes, including degenerative changes, trauma, tumors, or congenital dysplasia. ${ }^{1-3}$ Isthmic spondylolisthesis is an acquired condition that results from a pars interarticularis disruption, usually at the L5 vertebra, and exhibits similar male and female distribution. Depending on the severity, the most common symptoms are low-back pain and unilat- eral or bilateral leg pain caused by L5 radiculopathy. ${ }^{3,4}$ The first classification of spondylolisthesis was developed in 1932 by Meyerding et $\mathrm{al}^{5}$ who described four types, or "grades", that are dependent on the degree of slippage between two vertebral bodies. In this classification, grade I involves a slip of $0 \%$ to $25 \%$, grade II is defined as $25 \%$ to $50 \%$ (grades I and II are both considered low-grade spondylolisthesis; that is, less than $50 \%$ slippage), grade III is defined as $50 \%$ to $75 \%$, and grade IV is defined as $75 \%$ to $100 \%$. Later, grade $V$ was added for slippage greater than $100 \%$ (grades III to $\mathrm{V}$ are 
considered high-grade spondylolisthesis; that is, greater than $50 \%$ slippage). ${ }^{5}$

The classification system of 6 types of progressive lumbosacral spondylolisthesis is based on radiographic parameters (ie, pelvic incidence, slip grade, and sacropelvic and spinal balance) and to propose a therapeutic guide for the management of these different types depending on spondylolisthesis severity. ${ }^{6,7}$ In 2011, the Spinal Deformity Study Group (SDSG) observed that many studies demonstrate the importance of global and spinopelvic balance, which is mainly assessed through radiographic measurements, such as pelvic incidence, sacral slope, pelvic tilt, sagittal vertical axis, and lumbar lordosis, in the evaluation and progression of spondylolisthesis. ${ }^{8-10}$

The relationship between pelvic and global balance and spondylolisthesis progression has garnered additional interest. Recent studies in the literature demonstrate a direct relationship between sagittal balance and health-related quality of life in patients with spinal deformities. ${ }^{6,11}$ The relationship between pelvic and global balance and spondylolisthesis progression has also attracted further clinical and scientific interest. ${ }^{12}$ A reliable study from the SDSG was carried out in adolescent patients with spondylolisthesis. ${ }^{6}$ In 2015 , Bao et a ${ }^{13}$ evaluated 80 patients, 70 of whom had isthmic spondylolisthesis and 10 of whom had dysplastic L5-S1 spondylolisthesis and showed substantial intraobserver and interobserver agreement of $86 \%(k=.83)$ and $73 \%$ $(k=.64)$, respectively. This classification also provides recommendations regarding slippage reduction in patients with high degrees of spondylolisthesis (types 4, 5, and 6). ${ }^{9}$ The authors recommended the following: no reduction in type 4 , attempted reduction (when possible) in type 5, and reduction and realignment in type 6 to restore spinopelvic and global balance. The rationale for this was that correction of spinopelvic and global parameters has been associated with pain relief and better quality of life in patients with spinal deformities. ${ }^{9,14,15}$

Surgical reduction in high-grade spondylolisthesis is more effective for postoperative maintenance and restoration of normal pelvic balance and postural stabilization; ${ }^{16}$ however, this remains a debatable procedure ${ }^{17,18}$ because of the high risk of complications. ${ }^{19}$ Reduction from high to low grade was associated with increased strain of the L5 spinal nerve root. $^{20} \mathrm{~A}$ study with 30 patients who underwent the procedure showed that the substantial majority (23 of the patients) experienced some degree of L5 neurologic deficit after the second stage of the procedure. Deficits were temporary in 21 patients, and 2 patients required ankle-foot orthosis for their L5 muscle group weakness. ${ }^{16,21}$ Schär et $\mathrm{al}^{22}$ carried out a transforaminal lumbar interbody fusion (TLIF) L5-S1 and posterior screw fixation in the majority of their patients to treat all types of high-grade spondylolistheses with reduction and fixation and found an incidence of $30 \%$ of new root deficits of L5.

Although the SDSG classification seems promising, we still lack robust clinical outcome studies ${ }^{4}$ to support the recommendations made by Mac-Thiong et al. ${ }^{6,7}$ Thus, follow-up studies on neurological complications with L5 radiculopathy using the SDSG classification still remain inconclusive in young adult patients with spondylolisthesis. Therefore, the questions asked in the current study were (1) is the preoperative presence of L5 radiculopathy in high-grade 5 and 6 spondylolisthesis by SDSG classification different from the postoperative presence after 6 weeks and 3 months of follow-up in young adult patients? And (2) is the preoperative presence of L5 radiculopathy in high-grade 5 and 6 spondylolisthesis by SDSG classification different from the postoperative presence after 6 months and 1 year of follow-up in young adult patients? Thus, the objective of this study was to assess the presence of L5 radiculopathy in high-grade L5-S1 spondylolisthesis in young adults in the pre and postoperative periods and after a 2-year follow-up.

\section{METHODS}

\section{Study Design and Participants}

This study is a retrospective cohort study with 2 years of follow-up. Sixteen patients were treated with reduction and transforaminal lumbar interbody fusion with pedicle screw fixation for highgrade 5 and L6 isthmic spondylolisthesis at a single institution (Public Hospital in the State of São Paulo, Brazil) according to an established evaluation and follow-up protocol from January 2018 to December 2019. The experimental procedure was reviewed and approved by the Departmental Research Committee of the Institute of Medical Assistance to the State Public Servant (registration number 3.631.139) in accordance with ethical guidelines and regulations of the Declaration of 

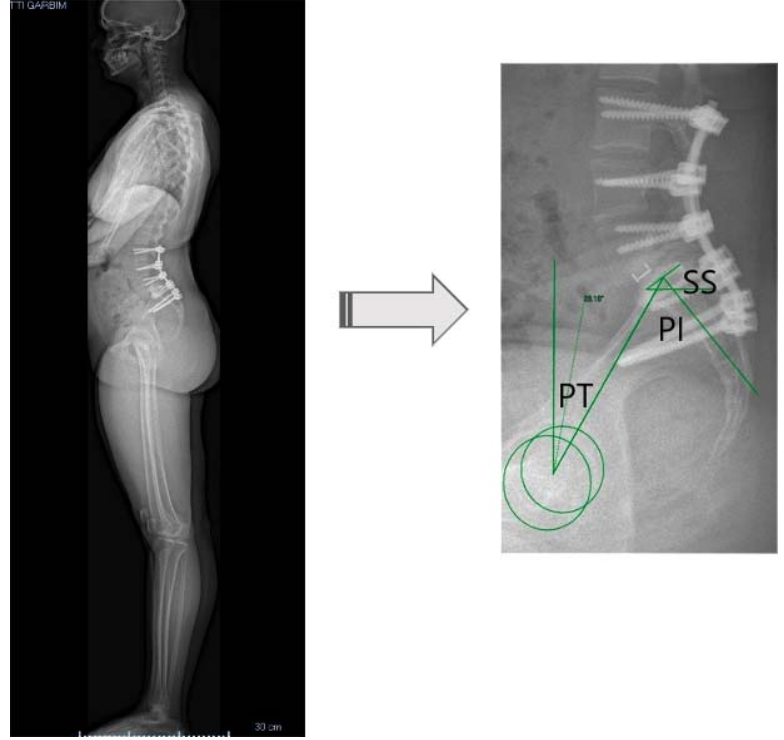

Figure 1. Postoperative radiography of a patient after surgery that included complete discectomy, L5-S1 transforaminal lumbar interbody fusion (TLIF) technique, and posterior L3-iliac transpedicular screws and rod fixation. The way of measuring spinopelvic parameters is highlighted. Abbreviations: PI, pelvic incidence; PT, pelvic tilt; SS, sacral slope.

Helsinki. All patients provided their informed consent and underwent radiographic assessment.

The following were used as inclusion criteria: (1) isthmic spondylolisthesis limited to L5-S1, (2) highgrade 5 and 6 isthmic spondylolisthesis with a formal indication of reduction, (3) undergoing a single type of surgical procedure to reduce and fix spondylolistheses (transforaminal lumbar interbody fusion with pedicle screw fixation), and (4) followup for a minimum of 24 months. The exclusion criteria were grade 4 or less isthmic spondylolistheses (SDSG), disorders affecting lower limb alignment, patients with incomplete data in the medical record, and those with previous surgery at the lumbar level.

\section{Surgical Technique}

Reduction was performed in all patients. A total atherectomy was performed by cutting the inferior and superior facet and, therefore, creating an open foraminotomy and decompressing the exiting L5 nerve root. Excessive fibrocartilaginous tissue was removed at the pars interarticularis defect as required for nerve root decompression.

Pedicle screw instrumentation was used to reduce the slipped vertebra with a drawing-back technique. In total, 4 patients underwent L3-iliac, 4 patients underwent L4-S1, 7 patients underwent L4-iliac, and 1 patient underwent L5-S1 posterior instrumentation with transpedicular screw. The pedicle screws were distracted to increase the interbody disk height. A complete discectomy with a TLIF technique was performed in all patients. Accordingly, a total facetectomy was performed by removing the inferior and superior facet and thereby creating an open foraminotomy and decompression of the exiting L5 nerve root. A unilateral kidney shape or two Harms cages were inserted into the disc space, according to the surgeon's judgment. Both the disc space and the cage were filled with autologous bone graft after thoroughly removing the intervertebral $\operatorname{disc}^{22}$ (Figure 1).

\section{Evaluations: Degree of Spondylolisthesis,} Radiographs, and Neurological Complications

Patients with spondylolisthesis were classified according to an SDSG classification that describes 6 types of lumbosacral spondylolisthesis based on slip grade and sacro-pelvic and global spino-pelvic balance (Table 1). The classification presents tested and confirmed validity and interater reliability. ${ }^{13}$

All patients were evaluated in the preoperative period and immediately after the surgical procedure, with follow-up after 6 weeks, 3 months, 6 months, and 1 and 2 years. Complete follow-up included plain radiographs and clinical scores. Panoramic anteroposterior and lateral radiographs of the spine were performed before surgery and after surgery at each follow-up visit. Spino-pelvic parameters (pelvic incidence, pelvic tilt, sacral slope, and sagittal balance) were measured on each radiograph. The clinical score was the presence of neurological

Table 1. Spinal Deformity Study Group classification of spondylolisthesis. ${ }^{a}$

\begin{tabular}{llll}
\hline Type & Slip Grade, $\%$ & \multicolumn{1}{c}{ Sacropelvic Balance } & Global Spinopelvic Balance \\
\hline 1 & $<50$ & Low pelvic incidence $\left(<45^{\circ}\right)$ & $\ldots$ \\
2 & $<50$ & Normal pelvic incidence $\left(<45^{\circ}-60^{\circ}\right)$ & $\ldots$ \\
3 & $<50$ & High pelvic incidence $\left(>60^{\circ}\right)$ & $\ldots$ \\
4 & $>50$ & Balanced (high sacral slope/low pelvic tilt) & Balanced (C7 plumb lies over or behind the femoral heads) \\
5 & $>50$ & Retroverted (low sacral slope/high pelvic tilt) & Unbalanced (C7 plumb lies in front of the femoral heads) \\
6 & $>50$ & Retroverted (low sacral slope/high pelvic tilt) & $\ldots$ \\
\hline
\end{tabular}

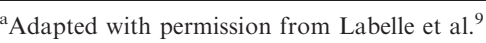


Table 2. Medical Research Council (MRC) muscle strength assessment scale. ${ }^{a}$

\begin{tabular}{ll}
\hline Degree & \multicolumn{1}{c}{ Muscle Strength Scale } \\
\hline 1 & No visible contraction \\
2 & Visible muscle contraction, but no limb movement \\
3 & Active movement, but not against gravity \\
4 & Active movement against gravity \\
5 & Active against gravity and resistance \\
6 & Active movement against gravity full resistance \\
\hline
\end{tabular}

${ }^{a}$ According to Medical Research Council. ${ }^{23}$

complications, defined as any new neurosensitive deficit or worsening of a pre-existing deficit that occurred after the surgical procedure. Motor neurological deficit was quantified using the Medical Research Council ${ }^{23}$ scale for muscle strength, which ranks the patient's muscle strength on a scale of 0 to 5 (Table 2), grade 4 paresis being defined as mild motor deficit, grade 3 paresis as moderate motor deficit, and muscle strength grade 2 or less as severe motor deficit. A deficit of L5 was identified clinically as a weakness of the long extensor muscle of the hallux or an objective paresthesia (observed by the examiner during the physical examination) in a dermatome (Table 2).

\section{Statistical Analysis}

We performed statistical analyses using SPSS1 for Windows 10 (version 14.0; SPSS Inc, Chicago, IL, USA). Depending on the variables, interobserver follow-up differences were analyzed using oneway analysis of variance for repeated measures and the Student $t$ test for pre- and postoperative clinical parameters. The result was considered statistically significant if the probability value was less than .05 .

\section{RESULTS}

Young adult patients were included, with a mean age of $20.1 \pm 12.0$ years. The mean preoperative L5S1 slip was $89.0 \%$. Of all patients, 5 presented neurological motor deficit with L5 radiculopathy in the preoperative period. In the immediate postoperative period, 9 patients $(56 \%)$ experienced new motor deficits or worsening of the preoperative deficit, while 1 patient presented improved preoperative deficit. At the 6-week follow-up, only 1 patient showed improvement in motor deficit. After 3 months, 3 patients presented healed motor deficits, and 1 additional patient demonstrated no L5 motor radiculopathy after 6 months. At the 1-year followup, only 1 patient exhibited an L5 radiculopathy motor deficit, and at the 2-year follow-up, no patients exhibited an L5 radiculopathy motor deficit (Tables 3, 4, and 5).

Four patients presented an L5 sensory deficit in the preoperative period, and 2 more demonstrated a new sensory deficit after the surgical procedure, totaling 6 patients with sensory deficit in the immediate postoperative period. After 2 years of follow-up, only 3 patients remained with mild paresthesia in the L5 dermatome region (18.7\%).

Tables 6 and 7 show that after 1 and 2 years of follow-up after the surgical reduction, significant differences were observed for reductions in slip and pelvic tilt as well as an increase in sacral slope compared with the preoperative period. Lumbar

Table 3. Pre- and postsurgery motor neurologic deficit.

\begin{tabular}{|c|c|c|c|c|c|c|c|c|c|c|}
\hline \multirow[b]{2}{*}{ No. } & \multirow[b]{2}{*}{ Sex } & \multirow[b]{2}{*}{ Age, $\mathbf{y}$} & \multirow[b]{2}{*}{ SDSG } & \multicolumn{7}{|c|}{ L5 Nerve Root Motor Deficit } \\
\hline & & & & Presurgery & Postsurgery & $\begin{array}{c}\text { Follow-Up, } \\
6 \text { Weeks }\end{array}$ & $\begin{array}{c}\text { Follow-Up, } \\
3 \text { Months }\end{array}$ & $\begin{array}{c}\text { Follow-Up, } \\
6 \text { Months }\end{array}$ & $\begin{array}{c}\text { Follow-Up, } \\
1 \text { Year }\end{array}$ & $\begin{array}{c}\text { Follow-Up, } \\
2 \text { Years }\end{array}$ \\
\hline 1 & $\mathrm{~F}$ & 17 & 5 & No & Moderate & Mild & No & No & No & No \\
\hline 2 & $\mathrm{~F}$ & 30 & 5 & No & Moderate & No & No & No & No & No \\
\hline 3 & $\mathrm{~F}$ & 14 & 5 & No & Mild & Mild & Mild & Mild & No & No \\
\hline 4 & $\mathrm{~F}$ & 25 & 6 & No & Moderate & Moderate & No & No & No & No \\
\hline 5 & $\mathrm{~F}$ & 16 & 5 & Mild & Mild & Mild & No & No & No & No \\
\hline 6 & M & 12 & 6 & Mild & Severe & Mild & Mild & No & No & No \\
\hline 7 & $\mathrm{~F}$ & 14 & 5 & No & No & No & No & No & No & No \\
\hline 8 & $\mathrm{~F}$ & 52 & 5 & Mild & Moderate & Moderate & Mild & Mild & No & No \\
\hline 9 & $\mathrm{~F}$ & 13 & 5 & No & No & No & No & No & No & No \\
\hline 10 & $\mathrm{~F}$ & 13 & 5 & No & No & No & No & No & No & No \\
\hline 11 & $\mathrm{~F}$ & 15 & 5 & No & No & No & No & No & No & No \\
\hline 12 & $\mathrm{M}$ & 14 & 6 & Mild & Severe & Moderate & Mild & Mild & No & No \\
\hline 13 & $\mathrm{~F}$ & 15 & 5 & No & No & No & No & No & No & No \\
\hline 14 & $\mathrm{~F}$ & 28 & 5 & No & Severe & Moderate & Mild & No & No & No \\
\hline 15 & $\mathrm{~F}$ & 30 & 5 & No & No & No & No & No & No & No \\
\hline 16 & $\mathrm{~F}$ & 14 & 5 & Mild & No & No & No & No & No & No \\
\hline
\end{tabular}

Abbreviations: F, female; M, male; SDSG, classification grade Spinal Deformity Study Group. 
Table 4. Comparison between pre- and postsurgery periods of radiographic, clinical, and motor deficit parameters of the L5 nerve over the 1-and 2-year follow-up of young adult patients with spondylolisthesis.

\begin{tabular}{lccccccc}
\hline & Preoperative & \multicolumn{5}{c}{ Surgical Post Follow-Up } \\
\cline { 3 - 6 } Parameters & Baseline & Postsurgery & 6 Weeks & 3 Months & 6 Months & 1 and 2 Years & $\boldsymbol{P}$ Value \\
\hline Sensitive, \% & 100 & 43.75 & 18.75 & 18.75 & 12.50 & 0.0 \\
Motor deficit (L5-MRC), mean \pm SD & $4.7 \pm 0.5$ & $3.9 \pm 1.0$ & $4.3 \pm 0.8$ & $4.7 \pm 0.5$ & $4.9 \pm 0.3$ & $5.0 \pm 0.1$ & .013 \\
\hline
\end{tabular}

Abbreviations: MRC, Medical Research Council; SD, standard deviation.

${ }^{a}$ One-way analysis of variance for repeated measures with significant differences at $p<.005$.

lordosis also presented an increase; however, this was not significantly different from the preoperative period.

\section{DISCUSSION}

In the literature, the complications of L5 neurological motor deficit after surgical treatment of severe spondylolistheses are well documented based on the Meyerding classification. ${ }^{22-27}$ The difference of this study was to show the reduction in complications of L5 neurological motor deficit over a 2-year follow-up in high degrees of spondylolisthesis (5 and 6, that is, balanced and unbalanced Pumble C7 line between femoral heads and sacrum) according to the classification of the SDSG. ${ }^{9}$

Although the L5 motor deficit has been documented in the clinical and scientific literature, ${ }^{28}$ there is wide variation in the prevalence after surgical reduction of high-grade spondylolisthesis. Detailed data on motor deficit are scarce in young adults, as the majority are directed to the pediatric population. $^{29-34}$ In young adults, there is little evidence of motor complications after surgical reduction of high-grade spondylolisthesis, especially for type 5 and 6 classifications. ${ }^{35-37}$ Among the studies observed in the literature, a retrospective study with 165 patients submitted to high-grade spondylolisthesis reduction (4 and 5$)^{25}$ showed an occurrence of $11.5 \%$ of new root neurological deficits after surgery, with motor deficit from L5 being the most common complication. ${ }^{38}$ Another study with a systematic review performed by Longo et $\mathrm{al}^{26}$ did not observe a statistically significant difference in neurological deficit at L5 between patients who underwent arthrodesis in situ and those who underwent sliding $(7.8 \%$ and $8.9 \%$, respectively). In the present study, the presence of neurological deficits at L5 were observed in patients with spondylolisthesis (5 and 6, SDSG) who underwent surgical treatment with reduction and fixation; however, the neurological motor deficits at L5 were significantly reduced after 3 and 6 months and especially 1 year after the surgery.

According to Schär et $\mathrm{al}^{22}$ cases of L5 deficit after reduction and fixation of high-grade spondylolistheses recovered spontaneously from the L5

Table 5. Pre- and postsurgery sensitive neurologic deficit.

\begin{tabular}{|c|c|c|c|c|c|c|c|c|c|c|}
\hline \multirow[b]{2}{*}{ No. } & \multirow[b]{2}{*}{ Sex } & \multirow[b]{2}{*}{ Age, y } & \multirow[b]{2}{*}{ SDSG } & \multicolumn{7}{|c|}{ L5 Nerve Root Sensitive Deficit } \\
\hline & & & & Presurgery & Postsurgery & $\begin{array}{c}\text { Follow-Up, } \\
6 \text { Weeks }\end{array}$ & $\begin{array}{c}\text { Follow-Up, } \\
3 \text { Months }\end{array}$ & $\begin{array}{c}\text { Follow-Up, } \\
6 \text { Months }\end{array}$ & $\begin{array}{c}\text { Follow-Up, } \\
1 \text { Year }\end{array}$ & $\begin{array}{c}\text { Follow-Up, } \\
2 \text { Year }\end{array}$ \\
\hline 1 & $\mathrm{~F}$ & 17 & 5 & No & Yes & Yes & Yes & No & No & No \\
\hline 2 & $\mathrm{~F}$ & 30 & 5 & No & No & No & No & No & No & No \\
\hline 3 & $\mathrm{~F}$ & 14 & 5 & Yes & Yes & Yes & Yes & Yes & No & No \\
\hline 4 & $\mathrm{~F}$ & 25 & 6 & No & Yes & No & No & No & No & No \\
\hline 5 & $\mathrm{~F}$ & 16 & 5 & No & No & No & No & No & No & No \\
\hline 6 & M & 12 & 6 & Yes & Yes & Yes & No & No & No & No \\
\hline 7 & $\mathrm{~F}$ & 14 & 5 & No & No & No & No & No & No & No \\
\hline 8 & $\mathrm{~F}$ & 52 & 5 & Yes & Yes & Yes & No & No & No & No \\
\hline 9 & $\mathrm{~F}$ & 13 & 5 & No & No & No & No & No & No & No \\
\hline 10 & $\mathrm{~F}$ & 13 & 5 & No & No & No & No & No & No & No \\
\hline 11 & $\mathrm{~F}$ & 15 & 5 & No & No & No & No & No & No & No \\
\hline 12 & $\mathrm{M}$ & 14 & 6 & Yes & Yes & Yes & No & No & No & No \\
\hline 13 & $\mathrm{~F}$ & 15 & 5 & No & No & No & No & No & No & No \\
\hline 14 & $\mathrm{~F}$ & 28 & 5 & No & Yes & Yes & Yes & No & No & No \\
\hline 15 & $\mathrm{~F}$ & 30 & 5 & No & Yes & No & No & No & No & No \\
\hline 16 & $\mathrm{~F}$ & 14 & 5 & Yes & Yes & No & No & No & No & No \\
\hline
\end{tabular}

Abbreviations: F, female; M, male; SDSG, classification grade Spinal Deformity Study Group. 
Table 6. Comparison between preoperative and postoperative periods of radiographic clinical parameters of the of young adult patients with spondylolisthesis.

\begin{tabular}{|c|c|c|c|}
\hline \multirow{2}{*}{$\begin{array}{l}\text { Radiography } \\
\text { Image } \\
\text { Parameters }\end{array}$} & \multicolumn{2}{|c|}{$\begin{array}{l}\text { Surgical Post Follow-Up } \\
\text { (12 and } 24 \text { Months), } \\
\text { Mean } \pm \text { SD }\end{array}$} & \multirow[b]{2}{*}{$P$ Value $^{\mathrm{a}}$} \\
\hline & Preoperative & Postoperative & \\
\hline Slip, \% & $89.0 \pm 9.3$ & $22.1 \pm 15.8$ & .012 \\
\hline Pelvic tilt, ${ }^{\circ}$ & $30.2 \pm 7.9$ & $19.8 \pm 4.3$ & .001 \\
\hline Sacral slope ${ }^{\circ}$ & $39.5 \pm 9.5$ & $50.0 \pm 8.0$ & .003 \\
\hline Lumbar lordosis, ${ }^{\circ}$ & $59.4 \pm 8.2$ & $63.0 \pm 7.6$ & .094 \\
\hline
\end{tabular}

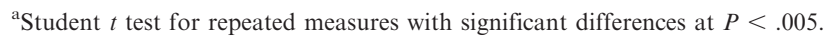

motor deficit in up to 3 months postoperatively, including those patients with neurological deficit before surgery, with this recovery maintained in a 2year follow-up. Sailhan et $\mathrm{al}^{39}$ reported a $9 \%$ rate of new motor deficits at L5 in a series of 44 patients with high-grade spondylolistheses undergoing reduction and fixation without foraminal decompression, while only 1 patient developed a persistent motor deficit in the 15-month follow-up. Gong et $\mathrm{al}^{40}$, in a study with 16 patients with types 4,5 , and 6 SDSG spondylolisthesis, observed the presence of motor deficit at L5 in only 1 patient after the sliding reduction surgery procedure, which was reduced 4 weeks after the surgery. In the current study in patients with spondylolisthesis, the neurological motor deficits at L5 were present throughout the immediate postsurgical follow-up and after 6 weeks, but were reduced after 3 and 6 months and demonstrated a total recovery after 2 years of follow-up after surgery.

Table 7. Radiological findings on stand lateral $x$-ray films.

\begin{tabular}{|c|c|c|c|c|c|c|c|}
\hline No. & Sex & $\begin{array}{c}\text { Age, } \\
\mathbf{y}\end{array}$ & SDSG & $\begin{array}{c}\text { Pelvic } \\
\text { Incidence, } \\
\circ\end{array}$ & $\begin{array}{c}\text { Preoperative } \\
\text { Slip, } \\
\%\end{array}$ & $\begin{array}{c}\text { Postoperative } \\
\text { Slip, } \\
\%\end{array}$ & $\begin{array}{c}\text { Absolute } \\
\text { Slip } \\
\text { Reduction, } \\
\%\end{array}$ \\
\hline 1 & $\mathrm{~F}$ & 17 & 5 & 74 & 85 & 10 & 75 \\
\hline 2 & $\mathrm{~F}$ & 30 & 5 & 67 & 76 & 25 & 51 \\
\hline 3 & $\mathrm{~F}$ & 14 & 5 & 84 & 81 & 18 & 63 \\
\hline 4 & $\mathrm{~F}$ & 25 & 6 & 65 & 100 & 15 & 85 \\
\hline 5 & $\mathrm{~F}$ & 16 & 5 & 71 & 100 & 38 & 62 \\
\hline 6 & M & 12 & 6 & 77 & 100 & 20 & 80 \\
\hline 7 & $\mathrm{~F}$ & 14 & 5 & 61 & 82 & 7 & 75 \\
\hline 8 & $\mathrm{~F}$ & 52 & 5 & 72 & 80 & 10 & 70 \\
\hline 9 & $\mathrm{~F}$ & 13 & 5 & 63 & 95 & 18 & 77 \\
\hline 10 & $\mathrm{~F}$ & 13 & 5 & 65 & 90 & 12 & 78 \\
\hline 11 & $\mathrm{~F}$ & 15 & 5 & 86 & 96 & 45 & 51 \\
\hline 12 & $\mathrm{M}$ & 14 & 6 & 63 & 100 & 52 & 48 \\
\hline 13 & $\mathrm{~F}$ & 15 & 5 & 66 & 80 & 10 & 70 \\
\hline 14 & $\mathrm{~F}$ & 28 & 5 & 70 & 100 & 52 & 48 \\
\hline 15 & $\mathrm{~F}$ & 30 & 5 & 71 & 78 & 5 & 73 \\
\hline 16 & $\mathrm{~F}$ & 14 & 5 & 61 & 82 & 17 & 65 \\
\hline
\end{tabular}

Abbreviations: F, female; M, male; SDSG, classification grade Spinal Deformity Study Group.
According to the literature, complication rates in pediatric spine surgery are high (between 10\% and $15 \%$ ), with motor neurological deficit present in $7.3 \%$ of cases, corresponding to a higher prevalence of those who were not undergoing surgical reduction, which corresponds to $1.2 \%{ }^{41}$ The Meyerding classification, ${ }^{25}$ despite being widely used, says little about the sagittal balance of the spine, a key point for the success of surgical treatment. With the development of a new classification of the SDSG, the main biomechanical parameters of sagittal balance were included, such as the degree of slippage (low or high degree), the pelvic incidence (low, normal, or high), and the spino-pelvic balance (balanced or unbalanced) of patients with spondylolisthesis. Although it is not possible to use an algorithm that establishes a specific treatment for each group, for high-grade spondylolisthesis, it is suggested that forced attempts at reduction may not be necessary, and sagittal alignment obtained with arthrodesis and surgical instrumentation may be sufficient. ${ }^{4}$

In this context, in patients with high-grade slippage (types 5 and 6), reduction and realignment should preferably be attempted according to the sliding degree. In cases of a high degree of slippage, in which there are difficulties in surgical instrumentation and in the arthrodesis procedure, the postural reduction itself may be sufficient to obtain adequate spino-pelvic alignment. ${ }^{4,12}$ It is known in the literature that formal reduction and spino-pelvic alignment are mandatory according to the increase in the degree of slippage, with grades 5 and 6 being the most severely impaired sagittal alignment. ${ }^{4,6,7,12,34}$ In the present study, only high-grade slips requiring surgical reduction were included, being grades 5 or 6 SDSG, considered more severe for subsequent impairment of L5 motor deficit. The results showed that $67 \%$ of the patients evolved a motor deficit at L5; however, in all cases, there was spontaneous recovery over 2 years, showing that the main problem related to the reduction in these cases was self-limited.

When considering the reduction and fusion of high-grade spondylolisthesis, opinions regarding the surgical techniques proposed to avoid postoperative L5 radiculopathy are somewhat discordant. Whereas some authors are opposed to posterior decompression of neural elements to minimize L5 nerve root manipulation and increase fusion rates, ${ }^{30,39}$ posterior lumbar interbody fusion using two cages 
as well as TLIF using a single cage are both widely used. A main advantage of TLIF is the transforaminal approach to the disc space with less retraction of the dural sac and nerve root. ${ }^{22} \mathrm{~A}$ recent randomized controlled trial comparing posterior lumbar interbody fusion and TLIF for reduction of low- and high-grade adult isthmic spondylolisthesis showed that both techniques provide good clinical and radiological outcomes. ${ }^{42}$ In our series, we chose a bilateral TLIF approach with the use of two Harms cages in most cases for optimal anterior support if necessary. By using the TLIF technique, we were able to achieve a mean absolute slip reduction of $66.9 \%(89.0 \%$ to $22.1 \%)$ at the final follow-up.

The limitations of the current study are that it is a retrospective cohort study that did not include additional factors, such as level of physical activity or functionality periods of postoperative treatment, which might affect sensitivity and motor function. However, this study included a homogenous population of patients with respect to diagnosis, curve pattern, and preoperative radiographic values.

\section{CONCLUSION}

L5 radiculopathy was frequent preoperatively, and this frequency increased after reduction and instrumented fusion of 5 and 6 (SDSG) spondylolisthesis surgery at the immediate postoperative moment and after 6 weeks of follow-up. After 3 and 6 months, there were consecutive motor improvements in L5 radiculopathy. After 1 and 2 years of follow-up, no patients presented neurological motor deficit of L5 radiculopathy. In addition, there was a significant improvement after 1 and 2 years of follow-up in the radiological parameters of the spine, such as slip, pelvic tilt, and sacral slope.

\section{ACKNOWLEDGMENTS}

The authors acknowledge the help and support of all the participants and the Spine Group of the Institute of Medical Assistance to the State Public Hospital Servant in the state of São Paulo, Brazil, during the study.

\section{REFERENCES}

1. Marty C, Boisaubert B, Descamps H, et al. The sagittal anatomy of the sacrum among young adults, infants, and spondylolisthesis patients. Eur Spine J. 2002;11(2):119-125. doi:10.1007/s00586-001-0349-7

2. Wang Z, Parent S, Mac-Thiong J-M, Petit Y, Labelle H. Influence of sacral morphology in developmental spondylolisthesis. Spine (Phila Pa 1976). 2008;33(20):2185-2191. doi:10. 1097/BRS.0b013e3181857f70

3. Beck AW, Simpson AK. High-grade lumbar spondylolisthesis. Neurosurg Clin N Am. 2019;30(3):291-298. doi:10.1016/j. nec.2019.02.002

4. Willhuber GC, Kido G. Classification in brief: the Spinal Deformity Study Group classification of lumbosacral spondylolisthesis. Clin Orthop Relat Res. 2019; 478(3):1-4. doi:10.1097/ CORR.0000000000001005

5. Meyerding HW. Spondylolisthesis. Surg Gynecol Obstet. 1932;54:371-377.

6. Mac-Thiong JM, Duong L, Parent S, et al. Reliability of the Spinal Deformity Study Group classification of lumbosacral spondylolisthesis. Spine (Phila Pa 1976). 2012;37:E95-E102. doi:10.1097/BRS.0b013e3182233969

7. Mac-Thiong J-M, Labelle H. A proposal for a surgical classification of pediatric lumbosacral spondylolisthesis based on current literature. Eur Spine J. 2006;15:1425-1435. doi:10. 1007/s00586-006-0101-4

8. Hanson DS, Bridwell KH, Rhee JM, Lenke LG. Correlation of pelvic incidence with low- and high-grade isthmic spondylolisthesis. Spine (Phila Pa 1976). 2002;27:2026-2029. doi:10.1097/00007632-200209150-00011

9. Labelle H, Mac-Thiong JM, Roussouly P. Spino-pelvic sagittal balance of spondylolisthesis: a review and classification. Eur Spine J. 2011;20(Suppl 5):641-646. doi:10.1007/s00586-0111932-1

10. Legaye J, Duval-Beaupere G, Hecquet J, Marty C. Pelvic incidence: a fundamental pelvic parameter for three-dimensional regulation of spinal sagittal curves. Eur Spine J. 1998;7(2):99103. doi: $10.1007 / \mathrm{s} 005860050038$

11. Glassman SD, Bridwell K, Dimar JR, Horton W, Berven S, Schwab F. The impact of positive sagittal balance in adult spinal deformity. Spine (Phila Pa 1976). 2005;30:2024-2029. doi:10.1097/01.brs.0000179086.30449.96

12. Hresko MT, Labelle H, Roussouly P, Berthonnaud E. Classification of high-grade spondylolistheses based on pelvic version and spine balance: possible rationale for reduction. Spine (Phila Pa 1976). 2007;32(20):2208-2213. doi:10.1097 BRS.0b013e31814b2cee

13. Bao H, Yan P, Zhu W, et al. Validation and reliability analysis of the Spinal Deformity Study Group classification for L5-S1 lumbar spondylolisthesis. Spine (Phila Pa 1976). 2015;40(21):E1150-E1154. doi:10.1097/BRS.000000000000 1104

14. Schwab F, Patel A, Ungar B, Farcy JP, Lafage V. Adult spinal deformity postoperative standing imbalance: how much can you tolerate? An overview of key parameters in assessing alignment and planning corrective surgery. Spine (Phila $\mathrm{Pa}$ 1976). 2010;35(25):2224-2231. doi:10.1097/BRS.0b013e3181 ee6bd4

15. Videbaek TS, B̈unger CE, Henriksen M, Neils E, Christensen FB. Sagittal spinal balance after lumbar spinal fusion: the impact of anterior column support results from a randomized clinical trial with an eight- to thirteen-year radiographic follow-up. Spine (Phila Pa 1976). 2011;36(3):183-191. doi:10.1097/BRS.0b013e3181cc8fce

16. Alzakri A, Labelle H, Hresko MT, et al. Restoration of 
normal pelvic balance from surgical reduction in high-grade spondylolisthesis. Eur Spine J. 2019;28(1):2087-2094. doi:10. 1007/s00586-019-05973-8

17. Hoel RJ, Brenner RM, Polly DW. The challenge of creating lordosis in high-grade dysplastic spondylolisthesis. Neurosurg Clin N Am. 2018;29(3):375-387. doi:10.1016/j.nec. 2018.03.006

18. Joelson A, Danielson BI, Hedlund R, Wretenberg P, Frennered K. Sagittal balance and health-related quality of life three decades after in situ arthrodesis for high-grade isthmic spondylolisthesis. J Bone Joint Surg Am. 2018;100(16):13571365. doi:10.2106/JBJS.17.01415

19. Molinari RW, Bridwell KH, Lenke LG, Ungacta FF, Riew KD. Complications in the surgical treatment of pediatric high-grade, isthmic dysplastic spondylolisthesis. A comparison of three surgical approaches. Spine (Phila PA 1976). 1999;24(16):1701-1711. doi:10.1097/00007632-19990815000012

20. Petraco DM, Spivak JM, Cappadona JG, Kummer FJ, Neuwirth MG. An anatomic evaluation of L5 nerve stretch in spondylolisthesis reduction. Spine (Phila PA 1976). 1996;21(10):1133-1138. doi:10.1097/00007632-19960515000002

21. Gaines RW. L5 vertebrectomy for the surgical treatment of spondyloptosis: thirty cases in 25 years. Spine (Phila PA 1976). 2005;30(6 Suppl):S66-S70. doi:10.1097/01.brs. 0000155577.19606.df

22. Schar RT, Sutter M, Mannion AF, et al. Outcome of 15 radiculopathy after reduction and instrumental transforaminal lumbar interbody fusion of high-grade L5-S1 isthmic spondylolisthesis and the role of intraoperative neurophysiological monitoring. Eur Spine J. 2017;26(3):679-690. doi:10.1007/ s00586-017-4964-3

23. Compston A. Aids to the investigation of peripheral nerve injuries. Medical Research Council: Nerve Injuries Research Committee. His Majesty's Stationery Office: 1942; pp. 48 (iii) and 74 figures and 7 diagrams; with aids to the examination of the peripheral nervous system. By Michael O'Brien for the Guarantors of Brain. Saunders Elsevier: 2010; pp. [8] 64 and 94 Figures. Brain. 2010;133(10):2838-44. doi: 10. 1093/brain/awq270

24. Mac-Thiong JM, Labelle H. Reliability and development of a new classification of lumbosacral spondylolisthesis. Scoliosis. 2008;310(3):19. doi:10.1186/1748-7161-3-19

25. Meyerding HW. Low backache and sciatic pain associated with spondylolisthesis and protruded intervertebral disc: incidence, significant, and treatment. J Bone Joint Surg. 1941;23(2):461-470.

26. Longo UG, Loppini M, Romeo G. et al. Evidence-based surgical management of spondylolisthesis: reduction or arthrodesis in situ. J Bone Joint Surg Am. 2014;96(1):53-58. doi:10.2106/JBJS.L.01012

27. Kasliwal MK, Smith JS, Kanter A, et al. Management of high-grade spondylolisthesis. Neurosurg Clin $N \mathrm{Am}$. 2013;24(2):275-291. doi:10.1016/j.nec.2012.12.002

28. Bradford DS, Gotfried Y. Staged salvage reconstruction of grade-IV and V spondylolisthesis. J Bone Joint Surg Am. 1987;69(2):191-202.

29. Helenius I, Lamberg T, Osterman K, et al. Posterolateral, anterior, or circumferential fusion in situ for high-grade spondylolisthesis in young patients: a long-term evaluation using the Scoliosis Research Society questionnaire. Spine (Phila
PA 1976). 2006;31(2):190-196. doi:10.1097/01.brs.0000194843. 94071.09

30. Ruf M, Koch H, Melcher RP, Harms J. Anatomic reduction and monosegmental fusion in high-grade developmental spondylolisthesis. Spine (Phila PA 1976). 2006;31(3):269-274. doi:10.1055/s-2005-918189

31. Shufflebarger HL, Geck MJ. High-grade isthmic dysplastic spondylolisthesis: monosegmental surgical treatment. Spine (Phila PA 1976). 2005;30(6 Suppl):S42-S48. doi:10.1097/ 01.brs.0000155583.55856.f9

32. Bartolozzi P, Sandri A, Cassini M, Ricci M. One-stage posterior decompression/stabilization and trans-sacral interbody fusion after partial reduction for severe L5-S1 spondylolisthesis. Spine (Phila PA 1976). 2003;28(11):1135-1141. doi:10. 1097/01.BRS.0000067274.38273.5C

33. Hanson DS, Bridwell KH, Rhee JM, Lenke LG. Dowel fibular strut grafts for high-grade dysplastic isthmic spondylolisthesis. Spine (Phila PA 1976). 2002;27(18):1982-1988. doi:10. 1097/00007632-200209150-00005

34. Smith JA, Deviren V, Berven S, Kleinstueck F, Bradford DS. Clinical outcome of trans-sacral interbody fusion after partial reduction for high-grade L5-S1 spondylolisthesis. Spine (Phila PA 1976). 2001;26(20):2227-2234. doi:10.1097/ 00007632-200110150-00014

35. Goyal N, Wimberley DW, Hyatt A, et al. Radiographic and clinical outcomes after instrumented reduction and transforaminal lumbar interbody fusion of mid and high-grade isthmic spondylolisthesis. J Spinal Disord Tech. 2009;22(5):321327. doi:10.1097/BSD.0b013e318182cdab

36. Lamartina C, Zavatsky JM, Petruzzi M, Specchia N. Novel concepts in the evaluation and treatment of highdysplastic spondylolisthesis. Eur Spine J. 2009;18(Suppl 1):133-142. doi:10.1007/s00586-009-0984-y

37. Lakshmanan P, Ahuja S, Lewis M, Howes J, Davies PR. Transsacral screw fixation for high-grade spondylolisthesis. Spine J. 2009;9(12):1024-1029. doi:10.1016/j.spinee.2009. 08.456

38. Kasliwal MK, Smith JS, Shaffrey CI, et al. Short-term complications associated with surgery for high-grade spondylolisthesis in adults and pediatric patients: a report from the scoliosis research society morbidity and mortality database. Neurosurgery. 2012;71(1):109-116. doi:10.1227/NEU. 0b013e3182535881

39. Sailhan F, Gollogly S, Roussouly P. The radiographic results and neurologic complications of instrumented reduction and fusion of high-grade spondylolisthesis without decompression of the neural elements: a retrospective review of 44 patients. Spine (Phila Pa 1976). 2006;31(2):161-169. doi:10. 1097/01.brs.0000194780.17528.6b

40. Gong Q, Li T, Zeng J, Liu L, Liu H, Song Y. Application of reduction by posterior approach to treat severe spondylolisthesis. Zhongguo Xiu Fu Chong Jian Wai Ke Za Zhi. 2013;27(4):393-398.

41. Fu KM, Smith JS, Polly DW, et al. Scoliosis Research Society Morbidity and Mortality Committee. Morbidity and mortality associated with spinal surgery in children: a review of the Scoliosis Research Society morbidity and mortality database. J Neurosurg Pediatr. 2011;7(1):37-41.

42. Yang EZ, Xu JG, Liu XK, et al. An RCT study comparing the clinical and radiological outcomes with the use of PLIF or TLIF after instrumented reduction in adult isthmic 
spondylolisthesis. Eur Spine J. 2016;25(5):1587-1594. doi:10. 1007/s00586-015-4341-z

Disclosures and COI: The author(s) declare that they did not receive financial support for the research, authorship, and/or publication of this article and report no conflicts of interest.

Corresponding Author: Ana Paula Ribeiro, MD, PhD, University of São Paulo, r. Cipotânea, 51, Butantã, São Paulo 05360-160, Brazil. Phone: 55
11 99139-2168; Fax: 55 (11) 2141 8687; Email: apribeiro@usp.br or anapribeiro@prof.unisa.br

Published 19 August 2021

This manuscript is generously published free of charge by ISASS, the International Society for the Advancement of Spine Surgery. Copyright (c) 2021 ISASS. To see more or order reprints or permissions, see http://ijssurgery.com. 